\title{
National progress, sustainability and higher goals: the case of Bhutan's Gross National Happiness
}

\author{
Jigmi Y. Thinley ${ }^{1}$ and Janette Hartz-Karp $2^{2^{*}}$
}

\begin{abstract}
Background: The context of this study is the predominant global paradigm for measuring national progress, the Gross Domestic Product (GDP), which has resulted in an over-emphasis on production and consumption that in turn, is exhausting the planet's capacity to sustain life. This study examines the potential for a new paradigm of development that can propel human society in a more meaningful, sustainable direction.

Results: Critiques of the GDP are overviewed, but the key critique is that if sustainability, human survival, is our key goal, then GDP, aiming at boundless material wealth, is driving us in the wrong direction. To drive a new sustainable, more meaningful way of life, we need an overarching paradigm with integrated, localized indicators that are internationally accepted as the measures of each nation's progress. Bhutan's Gross National Happiness $(G N H)$ Index exemplifies this. Based on the lived experience of a key GNH instigator, its nine domains are explained: Living standard, Health, Education, Ecological diversity and resilience, Cultural diversity and resilience, Community vitality, Time use, Psychological wellbeing, and Good governance. These have informed and been informed by the Sustainable Development Goals. It is outlined how the GNH Index guides development, allocates resources according to the targets set, measures people's happiness, and measures progress over time and geography.

Conclusion: The economic paradigm underlying the GDP - that the purpose of life is to become rich - is enabling our unsustainability. To enable future sustainability, we need to reconceptualize our concept of national progress. Moreover, since sustainability is effectively a euphemism for survival, then surely, as intelligent, sensitive beings, shouldn't we be pursuing a higher, shared goal? For the Bhutanese, this is 'happiness' - a paradigm that encompasses the pursuit of meaningful societal progress by balancing the physical with mental, the material with spiritual, within a safe and stable environment, with the purpose of realizing happiness. Though the Bhutanese do not claim to have reached a state of national happiness, Bhutan has maintained happiness as its overriding goal, with the tool's philosophy, authority and accountability driving this in everyday life.
\end{abstract}

Keywords: Sustainability, gross domestic product (GDP), GDP critiques, Gross National Happiness (GNH), GNH index, Alternative development paradigms, Sustainable development goals (SDGs)

\section{Plain English summary}

This study examines the global model for measuring national progress, the Gross Domestic Product (GDP), which appears to assume that the purpose of life is to become rich. However, if we want to achieve a more sustainable future, one that that enables human survival, then this endless pursuit of material wealth is driving us

\footnotetext{
* Correspondence: j.hartz-karp@curtin.edu.au

${ }^{2}$ Curtin Univeristy Bentley, Kent St., Bentley 6102, Western Australia

Full list of author information is available at the end of the article
}

in the wrong direction. Moreover, as intelligent, feeling human beings, shouldn't we be aiming towards a higher goal than human survival? For the Bhutanese, this higher goal is 'happiness', which they describe as the pursuit of meaningful societal progress achieved by balancing physical with mental, and material with spiritual elements, within a safe and stable environment, with the purpose of realizing happiness. From the perspective of one of the instigators of Bhutan's Gross National Happiness, its nine domains are explained, together with how they are measured - the Global National Happiness Index - and

(c) The Author(s). 2019 Open Access This article is distributed under the terms of the Creative Commons Attribution 4.0 International License (http://creativecommons.org/licenses/by/4.0/), which permits unrestricted use, distribution, and 
how this Index guides development, allocates resources according to the targets set, measures people's happiness, and measures progress over time and location. This model shows how a higher goal, 'happiness', provides the authority and accountability to drive this in everyday life.

\section{Introduction}

What will it take to mend our societies and eradicate the existential threat we have become to ourselves? It is shocking that at this height of civilizational progress, humankind should have to concern itself with the primordial challenge of survival; that all of our proud achievements have failed to secure the future of interdependent life on this planet. Particularly damning is the glaring truth that this state of affairs is the cumulative result of our achievements since the industrial revolution [1].

This untenable situation is further exacerbated by the influx of humankind to cities. Already more than half the world's seven billion people live in cities, and by 2050 , urban areas will be home to nearly $70 \%$ of the global population [2]. As cities grow exponentially to contain this ever-increasing influx of city dwellers who, in turn, have ever-increasing expectations of better living conditions, including material wealth, the additional load that has and will place on our planet is overwhelming. According to the ecological footprint analysis, humans today use the equivalent of 1.7 planets to provide the resources we use and to absorb our waste. If this trend continues, in the 2030s we will need the equivalent of two earths to support us [3]. Indeed, there are those who worry that we may have crossed the tipping point from which there can be no reversal to the planet's exhausted capacity to sustain life. Given this conundrum, it is no wonder that trying to create more sustainable cities and nations in a more sustainable planet has become a desired end result. Considering this huge challenge, this article focuses on two key questions: The first is - how can sustainability become the driver of national progress? Sustainability, here refers to developing sustainable models necessary for both the human race and planet Earth to survive [4]. This leads to the second question - is sustainability the final end result we seek? We aspire to a more sustainable world, but sustainability, after all, is a euphemism for survival. As intelligent, sensitive beings, is there not a higher goal we all share that needs to be pursued seriously?

If survival is our first concern, then a key question we need to be asking is how we could reconceptualize our concept of national progress from one based on the economy to another of moving towards a more sustainable future. The Sustainable Development Goals, accepted globally, could provide such a reconceptualization of progress. However, to date, the SDGs are belatedly tacked onto to our societal systems rather than driving them. The driver of national progress is the economically based measure, Gross Domestic Product (GDP). Despite the possibilities offered by alternative national progress measures that focus on broader goals than the economy, the GDP reigns supreme. Thus, in our view, the overriding challenge faced by humankind today is the pervasive assumption that underlies the GDP and how we live - that the purpose of life in our world is to become rich - with governments having the role of leading their countries towards boundless material prosperity. With the overwhelming, often taken-for-granted adoption of the concept of GDP, the primary function in life is to be economically productive and to have growing income in order to be able to spend more and consume more, regardless of increasing debt, social costs, and increasing environmental degradation.

The notion that GDP provides a valid marker of how well a country and its people are doing is rarely contested by those who have power over budgets. Fueled by the ethics of consumerism and empowered by the deified market, GDP continues to propel the world towards economic prosperity at any cost. Most people feel we have become richer economically and crave more wealth. Our consumer based societies often use the ideal of achieving happiness as motivation for increasing consumption, i.e. the satisfaction of material desires = happiness. Segments of society do recognize that this equation of happiness is a misconception. Aren't our human needs far more than material wealth? Are we satisfied with what we have? Are we happy and becoming happier? How much more happiness has wealth brought to the affluent, industrialized societies? Are these countries confident of their future, their stability and sustained prosperity? Do the people living there feel like they are living the best possible life? The recent World Happiness Report 2018 would suggest not [5]. Levels of happiness in nations across the globe are at their lowest ebb in over a decade. Notably, the USA, ranked number 1 in terms of the world's total private wealth is far from one of the happiest nations in the world, descending from 14th in 2017 to 19th in 2019. This national indicator of feelings about life satisfaction has predicted national turmoil, uprisings, and surprise election results, none of which have been predicted by accepted and trusted economic indicators such GDP trajectories. Other statistics across the globe also highlight people's declining sense of wellbeing, including the rates of clinical depression, crippling anxiety, and other forms of mental illness, which are damning [6], with over a million people each year ending their life, at an average of one suicide every $40 \mathrm{~s}$ [6]. This extreme act of despair is no longer rare in both the richest and the poorest countries. How do we 
explain why survival has become our biggest concern? And how do we explain why people's declining feelings of wellbeing and life satisfaction across the globe barely register a bleep on the radar of world leaders?

It will take wise and courageous leadership to address these challenges: leadership willing to deeply and sincerely re-examine the economic paradigms that drive our world - the profoundly engrained beliefs that have lost their relevance in a world we have transformed. In-depth thinking about the meaning of a nation's progress will be critical, as well as the process to realize its intent, and to align the means with the end in mind. It will require different ways of thinking and cooperating to envision societies and a world capable of transcending economic, political and social divisiveness. Our predominant use of analytic, cause and effect problem solving will not be sufficient. Nor will waiting for charismatic leadership to make the changes we need. Leadership alone cannot effectively address the dynamic tensions underlying economic, social/cultural and environmental demands; and without public involvement, will have difficulty creating and enacting a meaningful national vision. Notably, the importance of public participation is also embedded in the Sustainable Development Goals, particularly \#17 [7]. The public capacity for critical thinking and working cooperatively will need to be fostered through ongoing opportunities for civic involvement in envisioning the future and in helping to resolve issues that matter. Deeper, more integrative thinking skills will need to be embedded to enable us to more creatively and cooperatively move forward. These include: contextual analysis - linking specific with broader patterns; transdisciplinary thinking - thinking across and making connections between disciplines; and systems thinking - understanding the undeniable interdependence of all life, and realization that living species are not organized as an opportunistic, hierarchical food chain, but rather, are in a cyclical, closed loop of mutually dependent relationships, where success at the cost of others is fraught [8]. While broader and deeper thinking and collaboration skills can help us to transcend our endemic societal divisiveness, creating more meaningful, life-giving visions to steer our national progress, we will still need the courage to enact those visions. The Bhutanese offer an example of a nation that has evolved an alternative vision - happiness as the purpose of living, and has developed ways to enact this vision via the holistic Gross National Happiness (GNH) Index - their indicator of national progress, which in turn drives decision-makers to align their budgets and policies towards achieving more meaningful national progress.

\section{The origins of gross National Happiness}

The Bhutanese resolved the question about the meaning of national progress in 1972, when their young king, barely 17 years old, ascended the throne of his medieval, feudal state. Faced with the challenge of leading his country to a better future, he searched for the best pathways. Dissatisfied with the prevalent development models, His Majesty Jigme Singye Wangchuck, who was to rule for three decades before abdicating at the age of 53, was left to search within his own mind and in the wisdom of his own people. He began consulting his people by traversing, on foot and horseback, his infrastructure-poor, mountainous kingdom. He discovered that while his people would welcome being led out of the misery of their material wants, they were not entirely poor. They were proud of their wealth of spirituality, cultural vitality and strong social integrity. This was furthered by their sense of security in their symbiotic relationship with the bountiful natural environment. $\mathrm{He}$ was struck by their sense of contentment even in extreme poverty and their singular desire for happiness.

Realizing the universality of the desire for happiness, the king became determined to find a way that could protect and preserve the people's cultural and spiritual wealth while bringing in change towards greater wellbeing of his people. He saw how similarly poor countries, driven by the imperative of economic development, were encumbered with high costs of environmental degradation, social dislocation, cultural erosion, spiritual impoverishment and even diminished national sovereignty. He decided that change for his people must be holistic and human centred [9].

It was this integrated thinking that led to the conception of Bhutan's development philosophy of Gross National Happiness (GNH). This new paradigm encompasses the pursuit of meaningful societal progress by balancing the physical with mental, the material with spiritual, within a safe and stable environment for the purpose of realizing happiness. This concept of happiness is very different from the popular notion of happiness as something frivolous and fleeting. Instead, $\mathrm{GNH}$ is a multidimensional measure of sustained human wellbeing across 9 domains: living standard, health, education, ecological diversity and resilience, cultural diversity and resilience, community vitality, time use, psychological wellbeing, and good governance [10]. The idea of happiness as a serious end-goal is not new. The pervasive importance of happiness to humankind was noted nearly 2400 years ago: 'Happiness is the meaning and purpose of life, the whole aim and end of human existence' (Aristotle).

Bhutan does not claim to be a country that has achieved gross national happiness. For both the people and government, poverty continues to be a challenge and life is a struggle. What separates the kingdom from the rest of the world is its choice of happiness as the purpose of development policy and endeavours. That does not mean that the state must assume the responsibility of purveying happiness to its people. The if and 
how of happiness is a private, personal choice. Rather, the primary responsibility of the state is accepted as the creation and promotion of equitable conditions that will enable all citizens to pursue and maximize happiness. This is an onerous charge for any government, especially those with limited resources. However, it is one to which successive Bhutanese governments have remained true.

Notably, Bhutan does not insist on GNH being the best global alternative to prevailing development paradigms. Indeed, after practicing it silently for more than two decades, it was only at the urging of the United Nations Development Programme (UNDP) that the concept of GNH was presented at the 1998 Asia-Pacific Millennium Summit in Seoul, Korea. Subsequently, GNH came under the scrutiny of the international media, which in turn attracted many academics and development experts, and stimulated the ongoing global discourse on the subject. In a world where anything and everything of value has to be quantifiable, the question of developing a clear set of indicators for GNH became inevitable. This led to the question of what is wrong with the preeminent indicator, Gross Domestic Product (GDP)? As a result of asking that question, there were critiques that $\mathrm{GNH}$ is an idealistic attempt to reverse development - the argument regularly used to resist other development alternatives [11]. The positive outcome of this questioning has been the continuous refinement and elaboration of the GNH concept as a dynamic proposition, with broad intellectual input [10].

\section{Critiques of the globally accepted measure of GDP and alternative paradigms}

While the GNH has its critiques as a measure, so does the GDP. When the concept of gross domestic product (GDP) was developed by Simon Kuznets as a single measure to understand a country's growth, it was initially designed to measure manufacturing [12]. However, now services account for around $70 \%$ of the economy of developed countries [13] and the GDP cannot adequately measure them. GDP measures output that is bought and sold, but many services are neither tangible nor tradeable. As a consequence, a large proportion of services are neither measured nor accounted for, for example housework and many caring services. In his bestselling economics handbook, Paul Samuelson dryly noted that a country's GDP goes down when a man marries his maid [14]. Other services are inadequately measured, such as financial activities, where measurement is circuitous; and housing that people own and live in, where measurement is imputed and inaccurate. Additionally, in today's technological world, increasing numbers of services that were previously paid for are now given away for free and hence are no longer included in the GDP. For example, in 2013, it was noted that US consumers annually enjoy about $\$ 100$ billion worth of online services for which they don't have to pay [15]. This has led some commentators to argue that the greatest challenge for GDP is to 'account for the vast changes in the quality and range of goods and services that we consume' [16].

In our view, however, a far greater challenge is that, despite critiques of the conceptual problems with the GDP being the overall measure of national progress, and hence the need for alternative measures with greater diversification than economic growth, GDP has remained the dominant value as an indicator of progress $[17,18]$. As the Nobel prizewinner for economics, Joseph Stiglitz concluded: "For much of the world, globalization as it has been managed seems like a pact with the devil. A few people in the country become wealthier; GDP statistics, for what they are worth, look better but ways of life and basic values are threatened" [19]. By over-emphasizing production goals and resultant consumption, our focus on GDP has exacerbated the over-exploitation of our globe's resources, which, as the UN [20] noted, has irreversible consequences. Along similar lines, Coyle (2014), highlighted concerns about environmental damage and unsustainable rates of natural resource extraction, suggesting the need for a human development index (HDI) that measured capabilities rather than income [21]. A "regular, official indicator of sustainability is urgently needed" [21].

Economists, even Kuznets himself, deemed the GDP to be an inappropriate measure for human welfare. In many ways, GDP and people's wellbeing are at crosspurposes. For example, the more people who are sick, the more work and jobs generated, the higher the GDP; the more natural disasters, the more rebuilding required, the more jobs and materials needed, the higher the GDP. Robert Kennedy memorably noted that a country's gross domestic product measures 'everything except that which makes life worthwhile' [22]. Despite this acknowledgement, and despite the development of alternative, far broader measurements of national progress, the GDP remains the overriding global measure of progress, including human wellbeing.

The GNH is not the only alternative measure of progress that has been developed. Bhutan's GNH Index measures social, cultural, spiritual, economic and environmental elements [10]. Other national progress measures that are offered as alternatives or supplements to the GDP are listed below:

- Green GDP - an economic growth index that takes into account environmental externalities of growth, such as pollution and congestion [23]. International comparisons and national comparisons over time 
are problematic. The main critique of Green GDP and its derivatives, below, is that there is no coherent inclusion or exclusion of factors contributing to or detracting from welfare. For example, physical and psychological wellbeing are not included.

- The Genuine Progress Indicator (GPI) - a Green GDP systems measure, including annual income, net savings, wealth and environment costs and benefits, with metrics involving the consolidation of 26 indicators. Because it is expressed in monetary units, it's more comparable to the GDP [12].

- Happy Planet Index (HPI) - includes subjective wellbeing measures and objective measures of life expectancy and ecological footprint. The HPI multiplies life satisfaction by life expectancy and divides the product by a measure of ecological impact [24].

- The OECD's Better Life Index [25] - another Green GDP example, with both subjective and objective measures, based on 11 topics: housing, incomes, jobs, community, education, environment, civic engagement, health, life stratification, safety and work-life balance. International comparisons are limited.

- Human Development Index (HDI) [26]) - a summary measure of average achievement of 3 dimensions of human development: a long and healthy life, being knowledgeable, and having a decent standard of living

- Sustainable Development Goal (SDG) Index and Dashboard [27] - collects data from 149 countries and provides a report card to track progress on the SDGs. It then ranks countries based on their progress towards the 17 global goals across economic development, social inclusion and environmental sustainability, underpinned by good governance.

- Wellbeing measures adopted as national indicators of progress, such as in the UK and France [18].

- The Canadian Index of Well-being (CIW) - a subjective measure of social progress. The CIW incorporates eight domains: arts, culture and recreation, community vitality, democratic engagement, education, environment, healthy populations, living standards and time use [28].

- In Italy, a joint initiative of Cnel and Istat - a measure of equitable and sustainable well-being using 12 dimensions of well-being: health, education and training, work and life balance, economic wellbeing, social relationship, politics and institutions, safety, subjective well-being, landscape and cultural heritage, environment, research and innovation, and quality of services [29]
- In New Zealand, the budget for fiscal year 20192020, allocated NZ \$3.8 billion in operational funding and NZ \$10.4 billion in capital funding for the Wellbeing Budget [30]. The areas, prioritised annually for budget expenditure include: mental health, child wellbeing, supporting Māori and pasifika aspirations, building a productive nation and transforming the economy.

Other alternative national progress indicators outlined in the literature include:

- Inclusive Wealth Report Measuring Progress Toward Sustainability [31]

- Social Progress Index [32]

- Net National Product, Wealth, and Social well-being, Environment and Development Economics [33]

- Multidimensional Poverty Index [34]

Alternative measures to the GDP have led to an international debate - "Beyond GDP" [35]. Notably, this discourse is often characterized by commentators as "anti-growth". More recent work by Stiglitz et al. [35] negates this claim, stressing that anti-growth is not the philosophy underlying "GDP and beyond". Rather, that GDP cannot measure progress if it is not measuring what is important to society. For example, the authors propose that if a more comprehensive and parsimonious dashboard of indicators had been adopted reflecting what we value as a society, it would have indicated stronger growth than that actually achieved by most countries in the aftermath of the Global Financial Crisis. Growth as measured by increased GDP numbers which reflects neither an increase in the well-being of most citizens, nor the degradation of the environment and depletion of natural resources, is not an effective measure of progress. It is hardly progress if the economy and its citizens are more insecure, people's trust in its institutions and society are eroded, and conflict in society increases. We should not be mesmerized by a number that cannot reflect the dimensions of national progress. Instead, our measurement focus needs to be on growth that is equitable and sustainable.

Despite the continuing debate, alternative measures to GDP have not gained international traction, and the GDP reigns supreme. This has significant repercussions since we know that what we measure drives behavior. The underlying assumption of the GDP - that the primary function of life is be economically productive with the role of governments being to lead their countries towards boundless material wealth - is propelling countries towards economic wealth but at an untenably high planetary cost. Our quarterly measure of economic 
growth against the GDP indicator does not include the negative externalities, while companies seldom fail to exaggerate their positive spill-overs. Our excessive production and consumption of every conceivable item, consigned soon thereafter to waste, has brought our globe to a dangerous tipping point. It is only now that the ecological, social and psychological costs as well as the unconscionable disregard for future generations have become alarmingly clear. From the time of Aristotle, it was thought that 'good living' within a 'virtuous society' was a noble pursuit. However, where material prosperity has become the purpose in life, more 'noble' human values and institutions have been and continue to be displaced. Family, community and relationships that form the very core and basis of society are disintegrating and with this, the prospect for happiness. Happiness, as a concept, has been trivialized and dismissed as unattainably utopian.

\section{GNH as an example of an alternative paradigm and measure of national progress}

Rather than measuring progress in economic terms only, Bhutan's GNH was initially anchored in the four pillars of economic growth, cultural vitality and diversity, environmental resilience and good governance. These have since been elaborated into an index of nine essential domains that are integrated, individually critical, mutually dependent and enriching. Collectively, they provide the basis for happiness and form the yardstick for Bhutan's progress in the development of happiness-enabling conditions for its citizens. The GNH Index, as such, exemplifies integrated thinking not least for the reason that it connects performance (national progress) with purpose (the pursuit of happiness - an end goal for humankind and the planet) through a process of in-depth analysis and discovery. The Bhutanese government uses integrated reporting as a way of stimulating integrated thinking and vice versa about how Bhutan can create value now and into the future. The nine indicators are described as follows [36]:

1. Living standard - indicating the population's basic economic condition. By gathering information on disposable income, the levels of material wealth or poverty experienced by different sectors of the population are determined and income inequalities are noted. Economic security is ascertained by collecting data on, for example, land ownership, food security and employment.

2. Health - measuring the physical health status of the population. In addition to life expectancy, mortality and morbidity rates, it incorporates individually reported health status and health risk behaviours. The status indicator of percentage reporting good/excellent health, although subjective, has been found to be a good predictor of disease incidence and mortality. Other examples of GNH status indicators include the percentage of the population sampled reporting healthy levels of physical activity and the percentage reporting healthy weight.

3. Education - reporting on a number of factors, including participation, skills and educational support; informal, non-formal and monastic education; and the national, community and family resources that influence education. Other examples include the percentage of the population sampled reporting strong skills and knowledge in at least five important areas, and the percentage reporting a high level of family, civic and cultural knowledge.

4. Ecological diversity and resilience - assessing the state of natural resources, the pressures on ecosystems, and different management responses. This domain describes domestic supply and demand and their consequences for Bhutan's ecosystems. In terms of supply, the surveys review the status of land, water, forest, air and biodiversity. In terms of consumption, the domain looks at factors such as production, waste, transportation, energy use and ecological footprint. As Bhutan orients its natural resource use towards sustainability, status indicators include the percentage of the population sampled reporting sustainable natural resource practices in their communities. The prevalence of sustainable resource use at the local level is measured, assisting in registering the effectiveness of renewable resource use policies. The impact of global warming and its threats are also being measured.

5. Cultural diversity and resilience - informing on the diversity and strength of cultural traditions in Bhutan. This takes into account the nature and number of cultural facilities, language use patterns and diversity, as well as participation in community-based religious activities. The surveys also review responses regarding core values, local customs and traditions, and changes in values. Thus, status indicators such as the percentage reporting good or excellent knowledge in a certain number of traditions reflect the degree to which members practice and maintain traditional skills and forms of knowledge.

6. Community vitality - focusing on the strengths and weaknesses of relationships and interaction within communities. Status indicators include the percentage reporting a high sense of trust in people, the percentage reporting a high level of vitality in the community, the percentage reporting voluntary activities, and the percentage reporting feelings of safety within their own home and community. These enable policymakers to track the changes in community vitality and help Bhutan to devise appropriate and timely strategies to prevent disintegration of community life and to strengthen social capital. In this regard, the family network is considered 
to be vitally important social capital. It is society's most resilient and sustainable form of economic, social and emotional safety net.

7. Time use - analyzing the manner in which time is spent within a 24-h period, and activities of longer duration. The data helps determine how the population spends its social, cultural, economic and human capital. From it, the percentage of time accorded to work, travel, food preparation, household chores and so on is calculated. Status indicators include the percentage reporting a satisfactory pace of life, time spent on community activities and time spent on social or family activities. One important function of time use is recognizing the value of leisure time.

8. Psychological wellbeing - encompassing contentment or satisfaction with various aspects of life, and health of the mind. As happiness is the main goal under a GNH society, psychological wellbeing is of primary importance to gauge the success of the state in providing appropriate policies and services. As psychological wellbeing of the population is an outcome of life circumstances related to societal conditions, it is also an indicator of wellbeing for the community and society as a whole. A holistic approach to development calls for inclusion of people's perceptions and state of mental wellbeing. A self-reported mean happiness score, based on a 10-point scale for international comparison, is one of the primary means of evaluating the sense of psychological wellbeing of citizens.

9. Good governance - evaluating five subdomains: participation in decision-making; effectiveness of government; just and equal law; freedom and quality of media; and transparency, accountability, honesty or corruption. Example status indicators are the percentage reporting participation in local government meetings, percentage reporting good/excellent performance of various levels of government, and percentage reporting trust in leaders and media. Each year, Parliament spends a full day discussing the results and determining where policies and actions are needed to resolve areas of deficit, or low happiness.

The purpose of the GNH Index is to set an alternative development framework: establishing indicators for each sector to guide development; allocating resources according to the targets set; measuring people's happiness; and measuring progress over time as well as over Bhutan's 20 judicial districts (dzongkhags). It is important that the domains and indicators are understandable to everyday people so they can serve not only as a policy tool, but also a way for people to envisage the different ways they can be happy in their lives. The full methodology and formulas of the GNH have been tabulated in an Appendix elsewhere [10] but can be understood in summary form as follows:
In respect to measurement, each of the domains are equally weighted, since each one is considered as important as the next. Each domain has a set of indicators, as follows:

1. Psychological wellbeing: Life satisfaction, Positive emotions, Negative emotions and Spirituality;

2. Health: Self-reported health, Healthy days, Disability, and Mental health;

3. Time Use: Work and Sleep;

4. Education: Literacy, Schooling. Knowledge, and Value;

5. Cultural Diversity and Resilience: Community skills and Cultural participation;

6. Good Governance: Political participation, Services, Government performance and Fundamental rights;

7. Community vitality: Donation (time and money), Safety, Community relationship, Family;

8. Ecological Vitality and Resilience: Wildlife damage, Urban issues, Responsibility towards environment, Ecological issues;

9. Living standard: Per capita income, Assets and Housing.

Unlike the domains that are equally weighted, the indicators listed above do not have equal weighting. For example, $10 \%$ for Fundamental rights, and Ecological issues, compared with $50 \%$ for Work and Sleep. Concommitantly, the subjective self-reported indicators are weighted more lightly than the objective measures. There are subjective, self-reported measures for each indicator. So, for example, in the Psychological wellbeing domain, the Life satisfaction indicator has four subjective measures: health, occupation, family standard of living and work-life balance. In order to determine where happiness lies, two thresholds have been developed. The first is the sufficiency threshold: who has enough. This is developed using international and national standards, and where not available, it relies upon normative judgements devised through a participatory process. The second is the happiness threshold. This allows for variations in the measurement of happiness.

In reporting the $\mathrm{GNH}$, the population is divided into four groups: the 'unhappy', the 'narrowly happy', the 'extensively happy' and the 'deeply happy'. Rather than selecting the lowest cut-off of around 10\% being 'unhappy', and hence requiring policy adjustments to address their needs, the middle happiness cut-off of $66 \%$ is selected, called 'not yet happy', which includes both the 'unhappy' and those who are 'narrowly happy'. In reporting, the results are stratified by gender, region, age and occupation. Profiles are also collected to provide qualitative understanding of different groups. 
Each of the above features is taken into account to determine what action to take. This process has six steps: 1) select the indicators; 2) apply the sufficiency threshold; 3) apply weights to each indicator; 4) apply the happiness threshold; 5) identify those who are happy and those who are not happy; and 6) apply a policy priority for those not yet happy. This last step is key to the raison d'être of the GNH. Every annual State of the Nation Report is submitted to the Parliament to inform, raise questions and concerns on how the nation is progressing on the ground. The government also developed a GNH policy-screening tool which mandates that every new policy, plan or project has to be evaluated against the nine domains and their indicators. To obtain government approval, a proposal must be GNH positive.

The GNH Index and philosophy underlying it, is understood to be a 'living experiment' [10]. It is constantly updated and modified as more is understood about 'happiness'. Accordingly, Bhutan has welcomed the assistance given from around the globe in developing and refining the Index. The GNH is not without detractors, however. Key critiques are summarized below, together with responses to these claims.

\section{Critiques of GNH and responses}

1. By implementing the $G N H$, it is a rejection of GDP. However, the Bhutanese reject this, pointing out that the GNH incorporates the GDP, using it to measure the state of development in the economic domain and its many variables. Indeed, this reflects the original intent of Simon Kuznet's standardized measure of GDP, warning specifically against equating its growth with wellbeing [37].

2. GNH measurement is strongly dependent on subjective data, often understood to be less scientifically rigorous than quantitative data. Respondents point to the precaution that 'not everything that can be counted counts, and not everything that counts can be counted' (often attributed to Einstein).

3. Aligned is the critique that the nature of happiness itself is a personal concept and hence is inevitably subjective, and as such is it not appropriate to guide the governance of any nation. Such distrust of subjective data has also fuelled most governments' neglecting to seriously consider happiness.

Disregarding subjective information frees governments from taking into account what should constitute their primary obligation of enabling the pursuit of wellbeing and happiness by their citizens. The GNH paradigm assumes that variability of happiness among people is critical in evaluating various aspects of governance. Where deep unhappiness exists, surely something is wrong.

4. Daga [38] notes additional critiques, including methodological critiques of the feasibility of GNH surveying in large, highly populated countries, especially considering the highly variable demographics of such countries, as well as the time and resource costs, including the lengthy completion time for each survey and around 9 months to complete the national survey in Bhutan. This feasibility critique certainly holds true for cities in developing countries with large numbers of informal residents, housing and employment, and lack of ready data to enable random sampling. Carrying out a rigorous survey methodology under such conditions is highly problematic.

5. Given the differences in nations' cultures and values, the GNH would not easily lend itself to global, cross country comparisons. While other measures could achieve this more easily, the intent and aligned process of the GNH make it inherently valuable.

\section{Positive impacts of $\mathrm{GNH}$}

On the positive side, the GNH exemplifies a holistic, all-encompassing index that serves to inform policy and decision-making for sustainable development in Bhutan. Specifically, it provides a way for the country to understand and enact progress based on the society's value of happiness. The GNH enables action at local, regional and national levels, as well as the ability to target specific disadvantaged groups and particular aspects of unhappiness needing attention. It provides Bhutan with a values-based method of focusing policies and budgetary allocation on those who need it most.

The GNH has influenced global politics, notably playing a role in the thinking and deliberations that led to the framing of the 17 Sustainable Development Goals for the 15-year period ending 2030. The UN Secretary General in 2013, Ban Ki-moon, advised that:

the new goal should embrace the emphasis on human wellbeing and include the use of metrics that go beyond standard income measures, such as surveys of subjective wellbeing and happiness, as introduced by many countries and the OECD [39].

Ban Ki-moon made note of countries and regions that have implemented human wellbeing metrics beyond income: France, Italy, Japan, Qatar, the UK and the European Union as well as Bhutan. Other countries in Asia, South America and the Middle East have also embraced the goal of human wellbeing, with the United Arab Emirates appointing a happiness minister. 


\section{The GNH as a way of integrating the 17 sustainable development goals}

The GNH domains and indicators clearly align with many of the individual SDGs. It exemplifies a reporting framework with integrated measurement that can inform and drive effective, cohesive policies, investments and decisions on the part of government, industry and commerce, as well as civil society and the community. The GNH offers some important lessons for integrated thinking and acting on the SDGs:

- The GNH Index is cyclical, with surveys administered annually, analysed and then deliberated by Parliament annually at a one-day session specifically dedicated to examining the results of the GNH. Accordingly, policies and budgets are set to address for the forthcoming year the key areas of concern. This is an effective way of institutionalizing the SDGs as an integral component of governance and a critical concern for the country.

- In terms of governance, the GNH has considerable 'buy-in' from the people, gained by involving the people in its conception, framing of the issues that are meaningful to them, with ongoing modification, and providing the quantitative and qualitative data that, when analysed, drives the country's agenda.

- Having an overarching driver - gross national happiness - is a key to the success of the GNH, and similarly can integrate and highlight the SDGs in ways that are locally and nationally meaningful. Each SDG is not simply something that gets scored at the national and international level to meet international obligations, but instead each target has local meaning, just as each domain of the GNH is either integral to the way of life of the Bhutanese or seen as a desirable goal. That is, the Index is also seen as an educative tool, to help people conceptualize what is encompassed by being 'happy' within the Bhutanese context of good living.

The GNH is a workable yet far-reaching mechanism to achieve the SDGs. It exemplifies integrated thinking for sustainability. The social, cultural, environmental, economic and governance aspects of the web of life are understood to be interrelated and integrated into the holistic concept of 'happiness'. Research is integrated with policy development and decision-making in a process that encourages reflexivity at every step. The GNH offers a different paradigm of how to aim towards a more livable world.

\section{Bhutan's progress towards gross national happiness}

It is uncertain whether the Bhutanese are happier now than before the adoption of GNH. Yet research has shown that the Bhutanese people are happy with the direction and the strategy it has given the country [40]. All Bhutan's development efforts have led to the strengthening of the four $\mathrm{GNH}$ pillars of economic growth, cultural vitality and diversity, environmental resilience and good governance. Thus far, Bhutan has managed to balance modernity with tradition and the material with mental, and it has made cautious steps towards growth that is sustainable. Bhutan's natural environment remains healthy and resilient with more than $72 \%$ of forest cover and just over half its territory declared as protected, thereby successfully conserving its extremely diverse flora and fauna [41]. Indeed, the constitution of the country mandates the maintenance of $60 \%$ of forest cover for perpetuity. Having started with a forest cover of $64 \%$ when Bhutan embarked on planned development in 1961, the country has been cited as proof that development need not come with ecological degradation. This success inspired Bhutan to make the daring pledge before the international community that Bhutan will forever remain carbon neutral.

Bhutan's cultural heritage, founded on basic human values, continues to guide both its thinking and everyday life. Its many manifestations are not in museums and tourist-attracting events but in the way Bhutanese live every day and the way they remain proud of their distinct identity. With the introduction of democracy, and the precedent of good governance under benevolent kings, responsive, efficient and accountable governance is a commitment of those in power and is a constant demand of the electorate. As Bhutan has now undergone its third general elections since the introduction of democracy, the Bhutanese people have experienced yet another peaceful transition of power.

Even with Bhutan's very cautious development process, the country has risen from the ignominy of being the poorest to a middle-income country, with the percentage of the population in poverty almost halved between 2007 and 2012 and continuing to decline [42]. Presently, Bhutan's GDP per capita is the third highest in South Asia after the Maldives and Sri Lanka. The Economist magazine ranked Bhutan as the fifth fastest growing economy in the world in 2013 and as the third best performing economy for 2018 with an estimated GDP growth of $7.6 \%$, far outpacing the average global rate of 4.4\% [43]. The 2017 Sustainable Development Goals progress report shows that Bhutan is doing reasonably well on these indicators and is listed among the top performers on poverty eradication [27].

In essence, GNH is more about qualitative life improvement than quantitative economic expansion. While this creates some constancy to the concept of happiness, it does continue to evolve with increasing information about what is known intuitively or proven scientifically. 
Currently, the concept of personal happiness tends to be accepted as comprising two aspects: the affective (the emotional) and the evaluative (life satisfaction). Together, they provide a subjective measure of an individual's or nation's wellbeing at a particular time. Overall, however, the concept of happiness involves the balance of material and non-material values, of co-existence with other people, living creatures and the environment.

\section{Conclusion}

The trivialization of happiness, we contend, has been one of the most damning mistakes society has made. When people dismiss happiness as a utopian fantasy, policy developers and decision-makers chase everything but what matters most to our wellbeing, fulfilment and happiness. The GNH Index refocuses attention away from mindless growth as the destination of humankind and the cities we create, and towards a shared ideal of humankind's happiness and the wellbeing of the planet. While it is true that Bhutan is not as highly urbanized as most countries, with only $41 \%$ of its population of around 817,000 people living in cities, this could give Bhutan the opportunity to leapfrog over the mistakes of most global urbanization, which have further precipitated our globe's unsustainability. Driven by the paradigm of happiness, Bhutan could demonstrate new ways of fostering human wellbeing while leaving behind a smaller ecological footprint.

The Bhutanese goal of happiness as the key signifier of the nation's progress shines a light on the deficiencies and pernicious consequences of the prevailing international acceptance of GDP as the measure of a nation's progress. The overriding goal of happiness supported by the GNH Index provides the government with a framework for exercising authority, devising plans, rules and processes that align with a clear sense of purpose and clear lines of accountability. Further, the Index not only integrates the SDGs, it also provides the government with the tools and philosophy to drive their pursuit in everyday life. With the GNH Index as the national scorecard for progress, the government has the mechanism to measure, report and act upon policies needed to address inequality and unsustainability, and aim towards universal wellbeing. It is an exemplar of planetary stewardship, so critical for our cities and our people, not just to survive but to thrive within a more balanced world.

\footnotetext{
Abbreviations

CIW: Canadian Index of Well-being; GDP: Gross Domestic Product; GNH: Gross National Happiness; GPI: Genuine Progress Indicator; HPI: Happy Planet Index; OECD: Organisation for Economic Cooperation and Development; SDGs: Sustainable Development Goals; UN: United nations; UNDP: United Nations Development Programme
}

Acknowledgements Not applicable.
Authors' contributions

The authors jointly conceived and designed the manuscript. All authors read and approved the final manuscript.

\section{Authors' information}

Hon Jigmi $Y$ Thinley served for 14 years in the Cabinet or as Prime Minister of Bhutan. During this time, the government established the research centre that developed the GNH Index and structured the National 5-year Development Plan on the GNH model of four pillars. Every annual State of the Nation Report was submitted to the Parliament to inform, raise questions and concerns on how the nation was progressing. After the development of the more elaborate GNH Index and regular GNH national surveys, the Bhutanese government developed a GNH policy-screening tool. This mandates that every new policy, plan or project will be evaluated against the nine domains and their subdomains. To obtain government approval, a proposal must be GNH positive.

Janette Hartz-Karp, a professor at Curtin University Sustainability Policy (CUSP) Institute, Western Australia, is a well-known practitioner, teacher and researcher in deliberative democracy. Janette worked over 4 years with a Western Australia Government Minister to implement deliberative democracy initiatives across the Planning and Infrastructure portfolio. She has also worked on deliberative democracy initiatives in Alberta Canada, Bangalore and Pune India, Be'er Sheva Israel, with the Club of Madrid, and currently in Kenya. Janette led a four-year research initiative on deliberative democracy to develop a more sustainable City-region, Greater Geraldton, WA. This work culminated in innovative participatory budgeting of the ten-year infrastructure budget and later, of 100\% of the City-Region's operational budget. The project received national and international acclaim.

\section{Funding}

The authors were supported during the writing of this manuscript by their respective institutions.

Availability of data and materials

The datasets analysed during the current study are available in the Citations.

Ethics approval and consent to participate

Not applicable.

Consent for publication

Not applicable.

\section{Competing interests}

The authors declare that they have no competing interests.

\section{Author details}

${ }^{1}$ Government of Bhutan, Thimphu, Bhutan. ${ }^{2}$ Curtin Univeristy Bentley, Kent St., Bentley 6102, Western Australia.

Received: 13 November 2018 Accepted: 20 November 2019 Published online: 30 December 2019

\section{References}

1. Thinley JY. Values and Development. Gross National Happiness. Seoul: The Millennium Meeting for Asia and the Pacific, (30 October - 1 November); 1998.

2. United Nations. World urbanization prospects: The 2014 revision, highlights. department of economic and social affairs. Population Division, United Nations. 2014

3. Global Footprint Network. Global Footprint Network, Advancing the Science of Sustainability: Recuperado el. 2013.

4. Brundtland GH, Khalid M, Agnelli S, Al-Athel S, Chidzero B. Our common future. New York: United Nations; 1987.

5. Helliwell J, Layard R, Sachs J. World happiness report. New York: Sustainable Development Solutions Network; 2018.

6. World Health Organization (WHO). Mental health. 2017. http://www.who.int/ mental_health/prevention/suicide/suicideprevent/en/. Accessed 7 Jun 2018.

7. United Nations. Sustainable development goals. 2014. Available at: https:// sustainabledevelopment.un.org/?menu=1300

8. Capra F. The web of life: a new understanding of living systems. New York: Doubleday; 1997. 
9. Thinley JY. GNH: reality or utopia? Paper presented at the University of Geneva; 2018.

10. Ura K, Alkire $\mathrm{S}$, Zangmo T, Wangdi K. A short guide to gross national happiness index: the Centre for Bhutan studies; 2012

11. The Economist. Bhutan the pursuit of happiness. 2004. https://www. economist.com/node/3445119. Accessed 4 Sept 2018.

12. Costanza R, Hart M, Talberth J, Posner S. Beyond GDP: The need for new measures of progress. The pardee papers; 2009.

13. World Bank. World Bank national accounts data, and OECD National Accounts data files. 2016. https://data.worldbank.org/indicator/NV.SRV.TETC. ZS?end=2016\&start=2016\&view=bar. Accessed 7 Jun 2018.

14. Samuelson PA. Economics: Tata McGraw Hill; 2010.

15. Hartford R. The gross distortions of GDP, financial times. 2013. https://www.ft. com/content/fadd10ea-6131-11e3-916e-00144feabdc0. Accessed 1 May 2018

16. Nordhaus WD. Do real-output and real-wage measures capture reality? The history of lighting suggests not. The economics of new goods: University of Chicago Press; 1996. p. 27-70.

17. Sen A. The idea of justice. J Hum Dev. 2008;9(3):331-42.

18. Stiglitz JE, Sen A, Fitoussi J-P. Report by the commission on the measurement of economic performance and social progress. Paris: Commission on the Measurement of Economic Performance and Social Progress; 2010.

19. Stiglitz J. Making globalization work. New York: WW Norton \& Company; 2006.

20. United Nations. The Future We Want, Outcomes of the UN Conference on Sustainable Development, Rio de Janeiro, 20-22 June, A/CONF.216/L.1. 2012. https://rio20.un.org/sites/rio20.un.org/files/a-conf.216l-1_english.pdf. Accessed 13 May 2018

21. Coyle D. GDP: a brief but affectionate history-revised and expanded edition. New Jersey: Princeton University Press; 2015.

22. Kennedy R. (1968). Remarks of Robert F. Kennedy at the University of Kansas. 1968. http://www.jfklibrary.org/Research/Research-Aids/ReadyReference/RFK-Speeches/Remarks-of-Robert-F-Kennedy-at-the-University-ofKansas-March-18-1968.aspx. Accessed 15 May 2018.

23. Verschuuren B, Subramanian SM, Hiemstra W. Community well-being in biocultural landscapes: are we living well?: practical action publishing; 2014.

24. New Economics Foundation. The Happy Planet Index: 2012 Report. A global index of sustainable well-being, vol. 12; 2012. p. 2015. http//www. Happyplanetindex.Org/ assets/happy-Planetindex-ReportPdf. Accessed 15 April 2018

25. Organization for Economic Cooperation and Development. How's life?: Measuring well-being. Paris: OECD Publishing; 2013.

26. United Nations. Human Development Index (HDI). 2018. Available at http:// hdr.undp.org/en/content/human-development-index-hdi

27. Sachs J, Schmidt-Traub G, Kroll C, Durand-Delacre D, Teksoz K. SDG index and dashboards - global report. New York: Bertelsmann Stiftung and Sustainable Development Solutions Network (SDSN); 2018.

28. Hogan MJ, Johnston H, Broome B, MCMoreland C, Walsh J, Smale B, et al. Consulting with citizens in the design of wellbeing measures and policies: lessons from a systems science application. Soc Indic Res. 2015; 123(3):857-77

29. Italian National Institute of Statistics. 12 dimentions of well-being. 2017. Available at: https://www4.istat.it/en/well-being-and-sustainability/wellbeing-measures/12-dimensions-of-well-being

30. Government of New Zealand. The Wellbeing Budget. 2019. Available at: https:/treasury.govt.nz/sites/default/files/2019-05/b19-wellbeing-budget.pdf

31. Managi S, Kumar P. editorsInclusive wealth report 2018: measuring progress towards sustainability. New York: Routledge; 2018.

32. Porter ME, Stern S, Green M. Social progress index 2014. Washington, DC: Social Progress Imperative; 2014.

33. Dasgupta P, Mäler KG. Net national product, wealth, and social well-being Environ Dev Econ. 2000;5(1):69-93.

34. Alkire S, Conconi A, Seth S. Multidimensional Poverty Index 2014: Brief methodological note and results; 2014.

35. Stiglitz J, Fitoussi J, Durand M. Beyond GDP: measuring what counts for economic and social performance. Paris: OECD Publishing; 2018. https://doi. org/10.1787/9789264307292-en.

36. Thinley JY. Instituting integrated thinking for sustainability: the case for Bhutan and its gross National Happiness. Paper presented at the Sustainable Integrated Cities International Conference. Western Australia: Curtin University; 2017.

37. Kuznets S. Economic growth and income inequality. Am Econ Rev. 1955; 45(1):1-28.
38. Daga G. Towards a new development paradigm: critical analysis of gross National Happiness; 2014

39. United Nations. General Assembly. Happiness: towards a holistic approach to development. GA/11116-A/65/PV. 109. 19 July 2011. Web. 14 May; 2013.

40. Helliwell J, Layard R, Sachs J. World happiness report. New York: Sustainable Development Solutions Network; 2012.

41. FAO. Global Forest Resources Assessment - Country profile Bhutan. 2015. http://www.fao.org/3/a-az168e.pdf. Accessed 15 Aug 2018.

42. Worldbank. Bhutan - Poverty Assessment 2014. 2014. http://documents. worldbank.org/curated/en/914381468013483608/pdf/90532 OWPOBhuta00Box385319B00PUBLIC0.pdf. Accessed 7 Jun 2018.

43. The Economist. The fastest-growing and shrinking economies in 2018. 2018. https://www.economist.com/blogs/graphicdetail/2018/01/daily-chart-3. Accessed 4 Sept 2018.

\section{Publisher's Note}

Springer Nature remains neutral with regard to jurisdictional claims in published maps and institutional affiliations.
Ready to submit your research? Choose BMC and benefit from:

- fast, convenient online submission

- thorough peer review by experienced researchers in your field

- rapid publication on acceptance

- support for research data, including large and complex data types

- gold Open Access which fosters wider collaboration and increased citations

- maximum visibility for your research: over $100 \mathrm{M}$ website views per year

At BMC, research is always in progress.

Learn more biomedcentral.com/submissions 